Table 1. Patient baseline characteristics

\begin{tabular}{|c|c|c|c|c|c|c|}
\hline & $\mathrm{RA}(\mathrm{N}=43)$ & & $\begin{array}{l}\operatorname{axSpA} \\
(\mathrm{N}=42)\end{array}$ & & PsA $(\mathrm{N}=38)$ & \\
\hline & Mean (SD) & Q1, Q3 & Mean (SD) & Q1, Q3 & Mean (SD) & Q1, Q3 \\
\hline Age (years) & $58.7(11.3)$ & 53,64 & $52.3(13.3)$ & 41,63 & $53.7(14.1)$ & 48,63 \\
\hline \multirow{2}{*}{$\begin{array}{l}\text { Duration of disease } \\
\text { (years) }\end{array}$} & $6.8(9.5)$ & 1,6 & $22.0(14.4)$ & $12.5,32.5$ & $13.8(9.4)$ & $5.5,22$ \\
\hline & $\mathrm{n}$ & $\%$ & $\mathrm{n}$ & $\%$ & $\mathrm{n}$ & $\%$ \\
\hline \multicolumn{7}{|l|}{$\begin{array}{l}\text { Dosing regimen ADA } \\
\text { to SB5: }\end{array}$} \\
\hline 40mg Q2W: 40mg Q2W & 34 & 85.0 & 36 & 85.7 & 34 & 89.5 \\
\hline Other & 6 & 15.0 & 6 & 14.3 & 4 & 10.5 \\
\hline $\begin{array}{l}\text { Stable disease (physician } \\
\text { opinion) }\end{array}$ & 34 & 91.9 & 27 & 65.9 & 30 & 85.7 \\
\hline Disease Activity Score: & Mean (SD) & $95 \% \mathrm{Cl}$ & Mean (SD) & $95 \% \mathrm{Cl}$ & Mean (SD) & $\begin{array}{c}95 \% \\
\mathrm{Cl}\end{array}$ \\
\hline DAS28 $(n=26)$ & $2.71(0.88)$ & $2.36,3.06$ & - & - & - & - \\
\hline $\begin{array}{l}\text { BASDAI }(n=31) \\
\text { PsA scores }(n=23)\end{array}$ & - & - & $3.71(2.89)$ & $2.65,4.77$ & $0.3^{-}(0.9)$ & - \\
\hline Swollen joint & & & & & $2.9(5.7)$ & $\begin{array}{l}-0.1 \\
0.8\end{array}$ \\
\hline Tender joint & & & & & & $\begin{array}{l}0.4 \\
5.4\end{array}$ \\
\hline Patient Awareness: & $\mathrm{n}$ & $\%$ & $\mathrm{n}$ & $\%$ & $\mathrm{n}$ & $\%$ \\
\hline $\begin{array}{l}\text { Instructed in } \\
\text { self-administration }\end{array}$ & 43 & 100.0 & 37 & 90.2 & 35 & 94.6 \\
\hline $\begin{array}{l}\text { Know to remove SB5 } \\
\text { from fridge } 30 \text { minutes } \\
\text { pre-injection }\end{array}$ & 43 & 100.0 & 38 & 95.0 & 36 & 97.3 \\
\hline $\begin{array}{l}\text { Know SB5 can be stored } \\
\text { out of fridge }<25^{\circ} \mathrm{C} \text { for } \\
28 \text { days }\end{array}$ & 42 & 97.7 & 33 & 82.5 & 28 & 75.7 \\
\hline
\end{tabular}

DAS-28 Disease Activity Score 28; BASDAI Bath Ankylosing Spondylitis Disease Activity Index; SD standard deviation; Q1 $1^{\text {st }}$ quartile, Q3 $3^{\text {rd }}$ quartile; Cl Confidence Interval

'Other' includes all other reported doses and/or dosing intervals: 40mg QW, 80mg Q2W, and unspecified frequency

Conclusion: This interim analysis provides a first insight into a contemporary cohort of EU patients with established RA, axSpA and PsA, switched from reference to biosimilar ADA in clinical practice. The majority of patients have stable disease at transition, $85 \%$ or more of each cohort transitioned to the same dose regimen of biosimilar as received for the reference prior to transition, and most are aware of correct storage and self-administration of their biosimilar medication. With ongoing enrolment and longer follow-up, the study will provide pertinent information about clinical outcomes of transition from reference to biosimilar adalimumab in real-world practice and in indications not investigated in controlled studies.

Disclosure of Interests: Ulf Müller-Ladner Speakers bureau: Biogen, Karl Gaffney Grant/research support from: AbbVie, Celgene, MSD, Novartis, Pfizer, and UCB Pharma, Consultant of: AbbVie, Celgene, MSD, Novartis, Pfizer, and UCB Pharma, Speakers bureau: AbbVie, Celgene, MSD, Novartis, Pfizer, and UCB Pharma, Deepak Jadon: None declared, Ulrich Freudensprung Shareholder of: Biogen International $\mathrm{GmbH}$, Employee of: Biogen International $\mathrm{GmbH}$, Janet Addison Shareholder of: Biogen Idec, Employee of: Biogen Idec DOI: 10.1136/annrheumdis-2020-eular.5429

\section{AB0312 REAL-LIFE DATA ON THE USE OF BIOLOGICAL DMARDS IN RHEUMATOID ARTHRITIS IN AUSTRIA WITH SPECIAL ATTENTION TO SWITCHING AFTER FIRST BDMARD FAILURE}

V. Nell-Duxneuner ${ }^{1,2,3}$, B. Reichardt ${ }^{4}$, T. Stamm ${ }^{3,5} .{ }^{1}$ Austrian Social Health Insurance Fund (österreichische Gesundheitskasse), Baden, Austria; ${ }^{2}$ Institute of Rheumatologie (IFR), Baden, Austria; ${ }^{3}$ Ludwig Boltzmann Institute Arthritis und Rehabilitation, Epidemiology, Vienna, Austria; ${ }^{4}$ Austrian Social Health Insurance Fund (österreichische Gesundheitskasse), Eisenstadt, Austria; ${ }^{5}$ Institute of Outcomes Research, Medical University of Vienna, Vienna, Austria

Background: The introduction of biological disease modifying anti-rheumatic drugs (bDMARDs) offered new dimensions in controlling disease progress for patients with Rheumatoid Arthritis (RA). According to the recommendations by EULAR, treatment should be commenced with a conventional synthetic DMARD as soon as diagnosis is made, followed by a bDMARD after treatment failure. The choice of drug is done in respect to comorbidities, preference of the patient and to costs. Objectives: Drug expenditure data of 2012-2016 were retrieved to evaluate frequency of prescription and drug survival with special focus on switching habits after first bDMARD failure.

Methods: Data were extracted from 11 Austrian social health insurance funds covering $86 \%$ of the Austrian population. Only patients with first prescriptions of bDMARDs were included. Absolute and relative frequencies of first bDMARD prescriptions, second and third courses of bDMARDs (switches) and probabilities of drug survival of first line bDMARDs were calculated. Baselines were set individually at the beginning of the first bDMARD course. A Sankey diagram was used to illustrate the relationships between first, second and third courses of bDMARDs (Figure). The first left column represents the first bDMARDs, the second and third columns the second and third switched bDMARDs, respectively. The quantity of the bDMARDs is reflected in the width of the lines.

Results: 7637 RA patients on bDMARD therapy were retrieved in total. With a presumed prevalence of $0.5 \%$ (Ref) this would account for $27 \%$ of RA patients being treated with a bDMARD. Of these, 3813 were first time prescriptions. The most commonly prescribed drug in bDMARD naïve patients was Etanercept with $26 \%$, followed by Adalimumab with $25 \%$. Third was Tocilizumab followed by Golimumab (16\% and 15\%), Abatacept with $9 \%$ and Certolizumab and Infliximab with both $4 \%$. Tocilizumab showed the longest drug survival with $80 \%$ after one and $61 \%$ of patients still on the drug after 3 years. Golimumab was clearly favorable among TNF inhibitors with a drug survival of $71 \%$ after one and $50 \%$ after 3 years compared to Certolizumab showing the lowest with $63 \%$ after one year and only $38 \%$ after three years. Tocilizumab was the drug most often switched to after first course failure, followed by Adalimumab. The choice of second bDMARD was different: After Adalimumab failure more patients were switched to another mode of action (almost 50\%), predominately Tocilizumab. This is also seen after Golimumab failure and is less pronounced in the other TNF inhibitors: they were mostly switched to second TNF inhibitor, mainly Adalimumab. The majority of patients started on Tocilizumab and Abatacept were switched to a TNF inhibitor ( $74 \%$ and $58 \%$, respectively). In third DMARD choice again Tocilizumab is mostly chosen followed by Abatacept, leaving $42 \%$ to a TNF inhibitor, mostly Golimumab.

Conclusion: Patients were most often started on a TNF inhibitor as first bDMARD, namely Etanercept and Adalimumab. Golimumab was prescribed less often but showed the longest drug survival among TNF inhibitors. Tocilizumab showed the longest drug survival overall and was the bDMARD most often switched to as second bDMARD. When starting with Adalimumab or Golimumab there was a tendency towards change of mode of action, which was not as pronounced for the other three TNF inhibitors. After failing twice Tocilizumab and Abatacept were the most often prescribed drugs.

\section{References:}

[1] Kobelt G, Fasteng F: Access to Innovative Treatments in Rheumatoid Arthritis in Europe. A Report prepared for the EFPIA, 2009

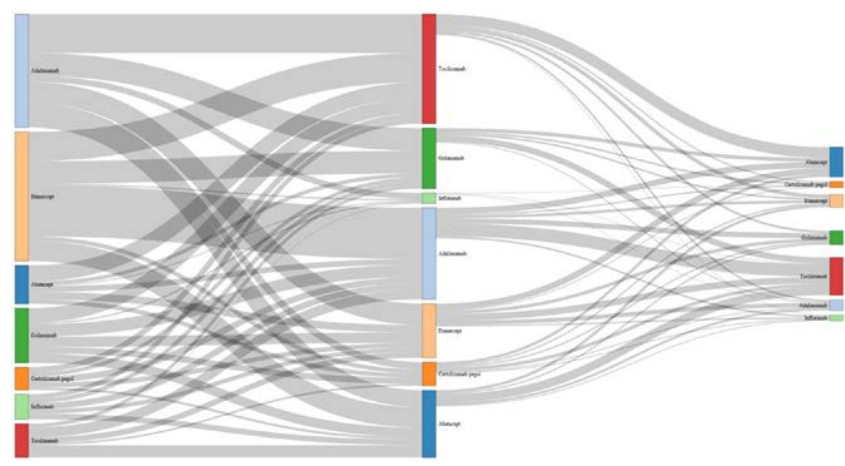

Acknowledgments: Austrian Main Social Health Association (Dachverband österreichische Sozialversciherung)

Disclosure of Interests: Valerie Nell-Duxneuner Speakers bureau: MSD, Pfizer, Jansen, Abbvie, Lilly, Novartis, Berthold Reichardt: None declared, Tanja Stamm Grant/research support from: AbbVie, Roche, Consultant of: AbbVie, Sanofi Genzyme, Speakers bureau: AbbVie, Roche, Sanof DOI: 10.1136/annrheumdis-2020-eular.5723

\section{$\mathrm{AB} 0313$ \\ CLINICAL PREDICTORS OF MULTIPLE FAILURES TO BIOLOGICAL THERAPY IN PATIENTS WITH RHEUMATOID ARTHRITIS.}

M. Novella-Navarro ${ }^{1}$, C. Plasencia ${ }^{1}$, C. Tornero ${ }^{1}$, K. N. Franco Gomez ${ }^{1}$, I. Monjo ${ }^{1}$, V. Navarro-Compán ${ }^{1}$, D. Peiteado ${ }^{1}$, A. Balsa ${ }^{1}$. ${ }^{1}$ Hospital Universitario La Paz, Rheumatology, Madrid, Spain

Background: Biological therapies have improved the clinical course and quality of life of Rheumatoid Arthritis (RA) patients. Despite the availability and effectiveness of these treatments, some patients present multiple failures to biologic disease-modifying anti-rheumatic drugs (bDMARDs), constituting a challenge to clinicians. 